Article

\title{
Experimental Evaluation of Distortion Effect for Grid-Connected PV Systems with Reference to Different Types of Electric Power Quantities
}

\author{
Marko Ikić $^{1,2, *}$ and Jovan Mikulović ${ }^{1}$ \\ 1 Faculty of Electrical Engineering, University of Belgrade, 11000 Belgrade, Serbia; mikulovic@etf.rs \\ 2 Faculty of Electrical Engineering, University of East Sarajevo, 71123 East Sarajevo, \\ Republic of Srpska, Bosnia and Herzegovina \\ * Correspondence: marko.ikic@etf.ues.rs.ba
}

check for updates

Citation: Ikić, M.; Mikulović, J. Experimental Evaluation of Distortion Effect for Grid-Connected PV Systems with Reference to Different Types of Electric Power Quantities. Energies 2022, 15, 416. https://doi.org/10.3390/en15020416 Academic Editor: Andrea Bonfiglio Received: 10 November 2021 Accepted: 3 January 2022 Published: 6 January 2022

Publisher's Note: MDPI stays neutral with regard to jurisdictional claims in published maps and institutional affiliations.

Copyright: (C) 2022 by the authors. Licensee MDPI, Basel, Switzerland. This article is an open access article distributed under the terms and conditions of the Creative Commons Attribution (CC BY) license (https:// creativecommons.org/licenses/by/ $4.0 /)$.

\begin{abstract}
Aware of the fact that the installed PV capacity and its power production rapidly increased in the last decade, with the huge impact that has been done to the power system, the distortion effects for grid-connected PV systems with reference to different types of electric power quantities will be presented in this article. The impact of the frequent fluctuation of solar irradiance on the behavior of the grid-connected PV system, due to cloud movements and resulting shadows and in terms of power quality and the evaluation of power components, is the topic of analysis in this research. Besides the simulation results of certain study cases, an experimental evaluation of electric power quantities on an actual PV system in real weather conditions was also performed. The experimental setup, formed through the combination of a PC and multifunctional I/O board with an appropriate software solution, was established and used for obtaining the target results. The methodology used for the evaluation of electric power quantities relied on the current physical components (CPC) theory for power definition. The experimental results were obtained for three different cases, namely, the low, medium, and high solar irradiance cases. On the basis of these results, the conclusions about distortion effects are given.
\end{abstract}

Keywords: grid-connected PV system; harmonics; CPC theory; electric power quantities

\section{Introduction}

In the last decade, the installation and production of photovoltaic (PV) systems have been increasing every year. Looking at the global trends, the cumulative installed PV capacity in 2020 was 707 GW, while electricity generation reached 844 TWh (Figure 1) [1]. The numbers, increased ten-fold, show that a significant influence of PV systems has been made on power systems. Photovoltaic technology is an attractive technology of renewable power generation and meets the new criteria of clean energy and sustainability. The conducted research and technology improvement have led to rapid progress in increasing the efficiency of photovoltaic modules and their optimization on the production of energy through better utilization of incident solar irradiance. Environmental conditions, as well as system design, have proven to be the most important factors in the operation of PV systems, and these can have a significant impact on the efficiency and power quality response of the whole system. The variable power flow, due to the fluctuation of solar irradiance (cloud movements and resulting shadows), temperature, and the topology of power converters are some of the parameters that affect the power quality of photovoltaic systems. These fluctuations can cause adverse effects, such as over/under-voltage issues, reverse power flow, and power quality issues [2]. Different mitigation methods have been developed and proposed for overcoming this issue, such as the local control of reactive power, use of volt-var control strategies, more efficient inverters, additional storage units, and the implementation of predictive control techniques. 


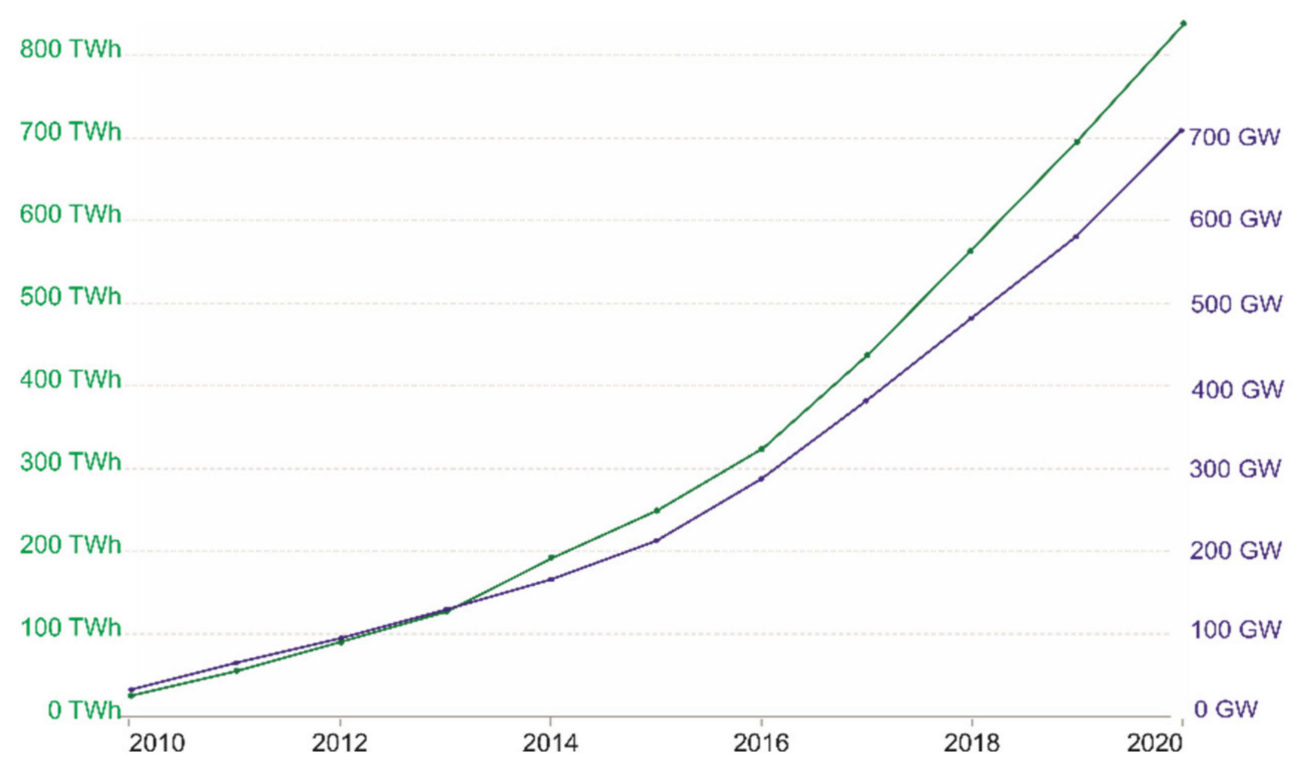

Figure 1. Global trends in the last decade: cumulative installed solar energy capacity (blue); electricity generation from solar (green).

Through a detailed analysis of the effect of solar irradiance on the power quality behavior of a grid-connected PV system, the authors signified in [3] that low solar irradiance can significantly affect the output of a PV system, maintaining the power factor at a low level due to comparable production of active and reactive power. In addition, the influence on distribution grids of large-scale as well as on rooftop PV systems can be found in references $[4,5]$.

The research conducted in [6,7] aims to characterize the power quality parameters of the grid-connected PV inverter under different operating modes, as well as focuses on the assessment and management of the power quality issues, to be fulfilled at the point of common coupling, as imposed by the new standards. According to the technical brochure [8], the harmonic emission of PV inverters can be divided into primary and secondary emissions, where the primary refers to the emission determined by the control algorithm implemented in the PV inverter, and the secondary is mainly caused by the characteristics of the grid side filter circuit of the PV inverter.

According to $[9,10]$, the researchers' tasks are mainly to investigate a novel strategy for power converter control in order to improve grid power quality. In [9], it is proposed that control of the Pulse-Width Modulation (PWM) inverter is a way to balance between active power production and power quality improvement without exceeding the whole system power capacity. The priority is set so that the first line preference has active power production, then reactive power compensation, and finally active filtering. Basic $p q$ theory (instantaneous active and reactive power components) is used to accomplish this task. Unlike previous research, ref. [10] developed an algorithm for the control structure of a PV inverter that operates as a shunt active power filter for supplying unbalanced and nonlinear loads. In addition, in very new research [11], power quality improvement in the hybrid renewable grid-connected system has become a promising research area. An intelligent control strategy is set up as an optimization solution for optimum power quality enhancement.

On the other hand, in the systems with harmonic distortions, voltage, and current asymmetries (i.e., nonlinear systems), the issue of non-active power identification is a topic that is still being debated in the wider academic community. In addition to this fact, the most convenient literature for power definition in the presence of harmonics is the IEEE Standard 1459-2010 [12]. This standard gives many definitions of power in three-phase 
systems, namely, of sinusoidal, balanced voltages, and currents; sinusoidal, unbalanced voltages, and currents; and nonsinusoidal, unbalanced voltages, and currents. As the grid-connected PV systems produce electric power with a significant share of current harmonics, especially in intervals with a low level of solar irradiance, these systems can be classified as nonlinear systems. As it is not uncommon that certain voltage asymmetries can appear in common coupling, the evaluation of electric power quantities is an additional task to understand.

In this contribution, the main set task is the evaluation of the electric power quantities of the grid-connected PV system depending on different levels of irradiance, which is not discussed in the literature so far. For an actual PV system, in real weather conditions, the weather condition dependence of electric power quantities will be presented, on the basis of the measurement values of voltages and currents for different cases, namely, low, medium, and high irradiance, and by applying the current physical components (CPC) theory for power definition [13-16]. In addition to the experimental results, the results obtained by a simulation model (developed for analysis and better understanding of the influence of the environmental and control parameters of the PV inverter on the distribution grid) are also given.

\section{Theoretical Background and Used Methodology}

\subsection{Used Methodology}

The major focus of this research, dealing with the impact of grid-connected PV systems, is based on power quality analysis and harmonic mitigation techniques [17-19]. In this article, the focus is on the evaluation of electric power quantities based on different solar irradiance levels. For that purpose, the first step was the creation of a simulation model of a real $15.9 \mathrm{kWp}$ residential grid-connected PV system. The system behavior was considered based on the analysis of the current harmonic injection into the grid and based on the selected topology and control structure.

An experimental measurement was performed and analyzed for three different cases (i.e., irradiance levels), followed by the different active power production, $\mathrm{THD}_{\mathrm{I}}$ factor, power factor $(\mathrm{PF})$, and the displacement power factor (DPF). These quantities were obtained based on power quality monitoring using a power quality analyzer Fluke 435 . The considered cases included low, medium, and high solar irradiance levels, as shown in Table 1, in order for the effects of the different irradiance levels on power quality to be observed. Measurement sampling was performed with a frequency of $50 \mu$ s; therefore, the measuring voltage and current values require large hardware resources. In addition, a numerical calculation of power quantities required a lot of time. Due to these reasons, the experimental results were presented with a 3 s measurement period.

Table 1. Three cases for evaluation of electric power quantities.

\begin{tabular}{|c|c|c|c|}
\hline & \multicolumn{3}{|c|}{ Irradiance Level } \\
\hline & $\begin{array}{c}\text { Low } \\
(<10 \% \text { of Nominal })\end{array}$ & $\begin{array}{c}\text { Medium } \\
(\approx \mathbf{5 0} \% \text { of Nominal })\end{array}$ & $\begin{array}{c}\text { High } \\
(100 \% \text { of Nominal) }\end{array}$ \\
\hline Time & 3 April 2021 at 5 p.m. & $\begin{array}{l}25 \text { March } 2021 \text { at } \\
10 \text { a.m. }\end{array}$ & $\begin{array}{c}25 \text { March } 2021 \text { at } \\
12 \text { a.m. }\end{array}$ \\
\hline Weather conditions & $70 \mathrm{~W} / \mathrm{m}^{2}, 15^{\circ} \mathrm{C}$ & $550 \mathrm{~W} / \mathrm{m}^{2}, 16^{\circ} \mathrm{C}$ & $1020 \mathrm{~W} / \mathrm{m}^{2}, 21^{\circ} \mathrm{C}$ \\
\hline
\end{tabular}

The CPC theory was selected for the evaluation of the electrical power quantities. This is because it provides a complete physical interpretation of power phenomena in electrical systems. Pursuant to the CPC theory for a three-phase nonsinusoidal and unbalanced system, the current decomposition is conducted by active $i_{\mathrm{a}}$, scattered $i_{\mathrm{s}}$, reactive $i_{\mathrm{r}}$, and unbalanced $i_{\mathrm{u}}$ current; Equations (1)-(4).

$$
i_{\mathrm{a} j}=\frac{P}{U^{2}} u=G_{e} u_{j}, \quad j=a, b, c
$$




$$
\begin{gathered}
i_{\mathrm{s} j}=\sum_{k=1}^{n}\left(G_{k}-G_{e}\right) u_{j k}, \quad j=a, b, c \\
i_{\mathrm{r} j}=\sum_{k=1}^{n} B_{k} \frac{d u_{j k}}{d\left(\omega_{k} t\right)}, \quad j=a, b, c \\
i_{\mathrm{u} j}=\sum_{k=1}^{n} \sqrt{2} \operatorname{Re}\left\{\left(\mathrm{I}_{j k}-Y_{k} \mathrm{U}_{j k}\right) e^{j \omega_{k} t}\right\}, \quad j=a, b, c
\end{gathered}
$$

where $G_{e}$ refers to the equivalent conductance with respect to the active power $P, G_{k}$ stands as the equivalent conductance at the frequency of the $k^{\text {th }}$ harmonic (different from $G_{e}$ ), and $B_{k} / Y_{k}$ is the equivalent susceptance/admittance at the frequency of the $k^{\text {th }}$ harmonic, respectively [14,15].

Appropriate power quantities can be calculated by using the root mean square (RMS) values of the above-mentioned current components.

$$
\begin{gathered}
D_{\mathrm{s}}=\sqrt{U_{a}^{2}+U_{b}^{2}+U_{c}^{2}} \cdot \sqrt{I_{\mathrm{s} a}^{2}+I_{\mathrm{s} b}^{2}+I_{\mathrm{sc}}^{2}} \\
Q=\sqrt{U_{a}^{2}+U_{b}^{2}+U_{c}^{2}} \cdot \sqrt{I_{\mathrm{r} a}^{2}+I_{\mathrm{rb}}^{2}+I_{\mathrm{rc}}^{2}} \\
D_{\mathrm{u}}=\sqrt{U_{a}^{2}+U_{b}^{2}+U_{c}^{2}} \cdot \sqrt{I_{\mathrm{u} a}^{2}+I_{\mathrm{u} b}^{2}+I_{\mathrm{u} c}^{2}}
\end{gathered}
$$

All these electric power quantities satisfy the orthogonality Equation (8):

$$
S^{2}=P^{2}+D_{s}^{2}+Q^{2}+D_{\mathrm{u}}^{2}
$$

The results of the evaluation of $\mathrm{PV}$ active power production $(P)$, total harmonic current distortion $\left(\mathrm{THD}_{\mathrm{I}}\right)$, power factor $(\mathrm{PF})$, and displacement power factor $(\mathrm{DPF})$ for different irradiance levels during three consecutive days are presented in Figure 2.

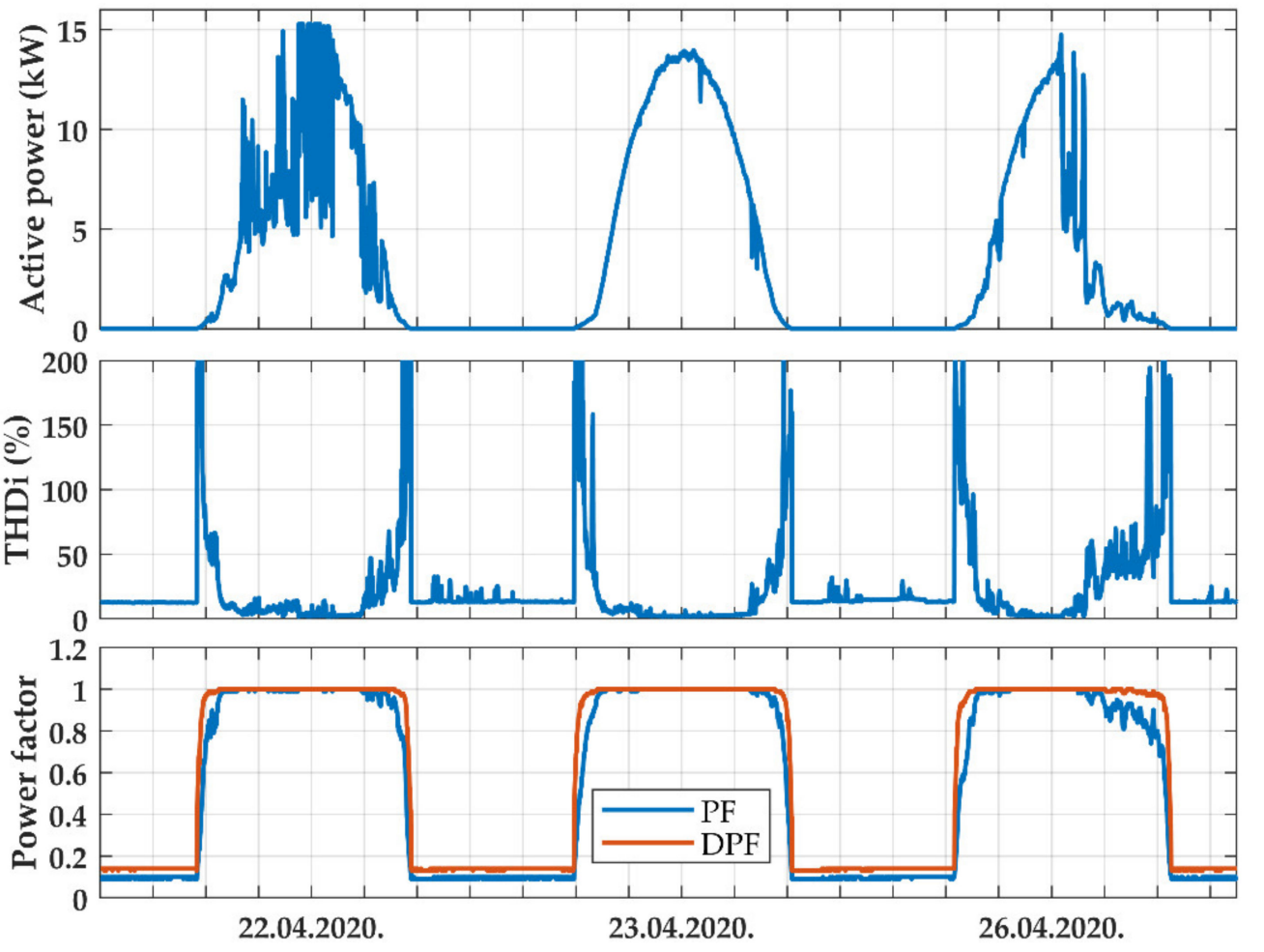

Figure 2. PV system production (active power) followed by changes in $\mathrm{THD}_{\mathrm{I}}$ factor, power factor $(\mathrm{PF})$, and displacement power factor (DPF) for different weather conditions. 


\subsection{Simulation Model}

A simulation of a real system process during the operation time was created. The simulation model of the grid-connected PV system was developed with the aim of testing and for a better understanding of the influence of environmental and control parameters on the distribution grid. In addition, the simulation results, as well as the experimental results (in real-time) might lead to better and more clarified research conclusions. For the observed grid-connected PV system of $15.9 \mathrm{kWp}$, a simulation model was created in MATLAB Simulink environmental. The simulation model of a grid-connected inverter as a double-stage three-phase topology was implemented. In the first stage, the maximum power of the PV array was obtained by using an MPPT (Maximum Power Point Tracking) converter designed as a Boost converter, on which the $\mathrm{P} \& \mathrm{O}$ algorithm for maximum powerpoint tracking was implemented. The second stage transformed DC to AC power through the three-phase inverter and reduced the content of higher harmonics from the inverter output with the grid filter (usually LCL). The control structure was based on well-known $d q$-reference frame technique [20-22], the block structure of which is shown in Figure 3. The PV inverters, connected to the distribution grid, were mostly set to produce only active power without reactive power control capability, so that the situation is modeled in this simulation.

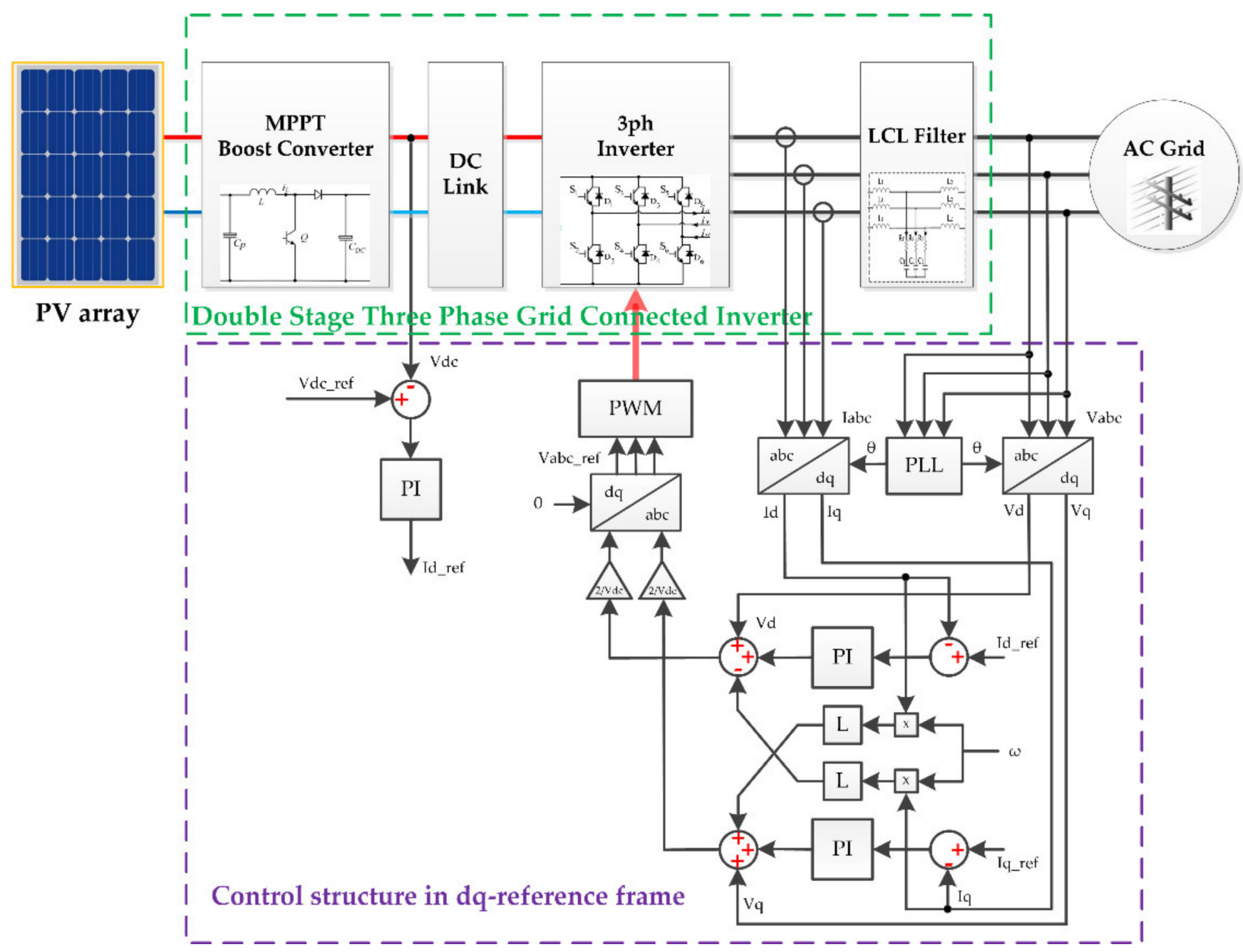

Figure 3. Block structure of grid-connected PV system model with double-stage three-phase inverter. 


\subsection{Simulation Results}

As mentioned previously, the control algorithms of a PV inverter cause the occurrence of high-order harmonics through switching operations, subsequently occurring as a current ripple. The level of the current ripple can be controlled by a grid-side filter, but this increases the losses in the inverter, i.e., reduces its efficiency. Modern PV inverters are implemented as double-stage converters. In the first stage, the MPPT function is implemented, and in the second stage, DC-AC conversion is performed. The MPPT function performs a constant change in the DC voltage level, which causes a change in the transfer function of the inverter and affects the generation of harmonic distortions of the current at the output terminals of the inverter. Previous studies demonstrate that the harmonic distortion of the inverter current mainly depends on the inverter load (irradiance level on PV array). In general, at a lower irradiance level, which corresponds to the lower PV power injection, the $\mathrm{THD}_{\mathrm{I}}$ factor is higher (Figure 2). As a result of the simulation work, there is a presentation of grid voltage and current waveforms for different irradiance levels (Figure 4a) as well as its corresponding harmonic spectra in the output current (for example, in Figure $4 b$, the harmonic spectra of the one-phase current are given).

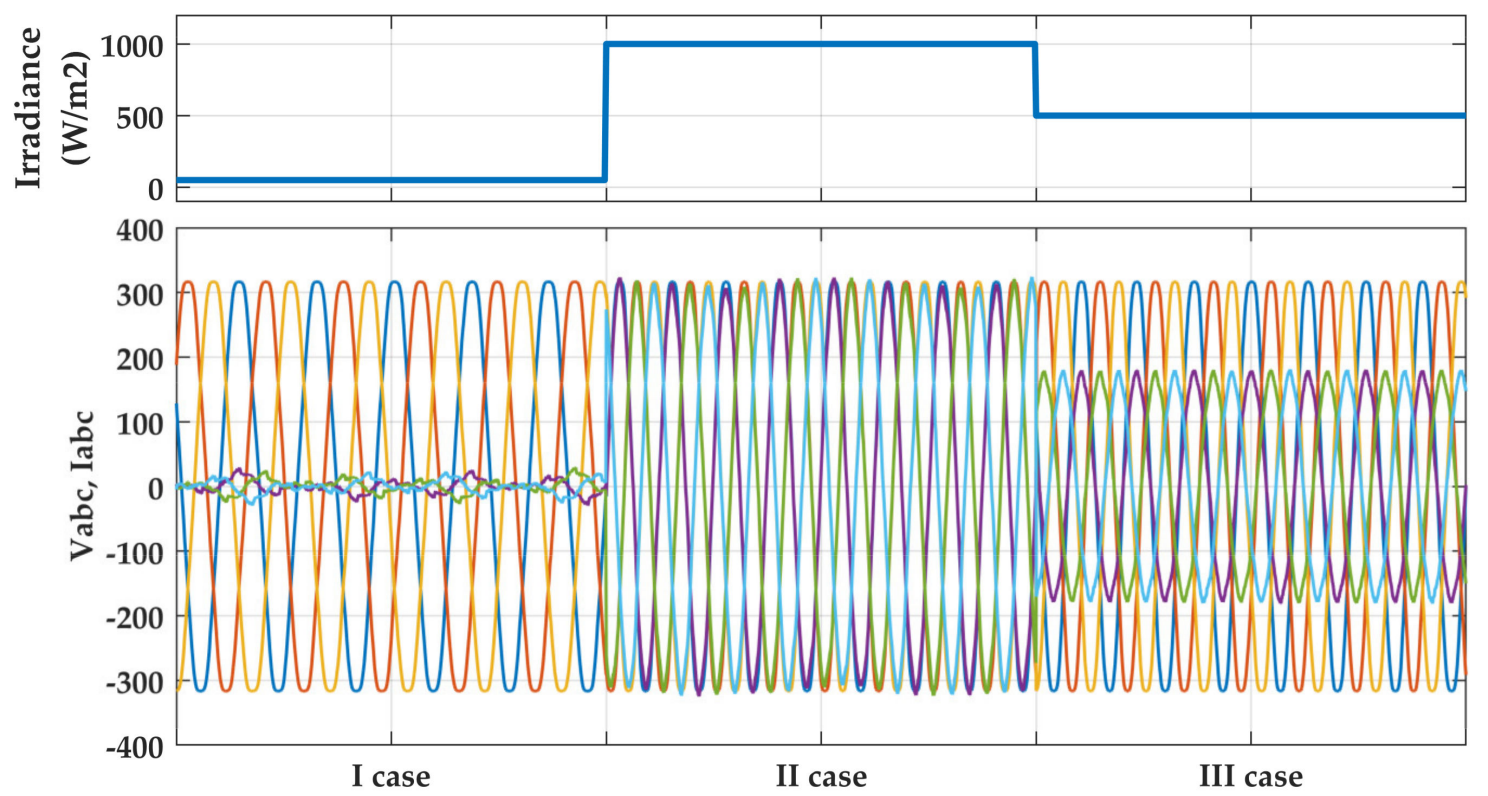

(a)
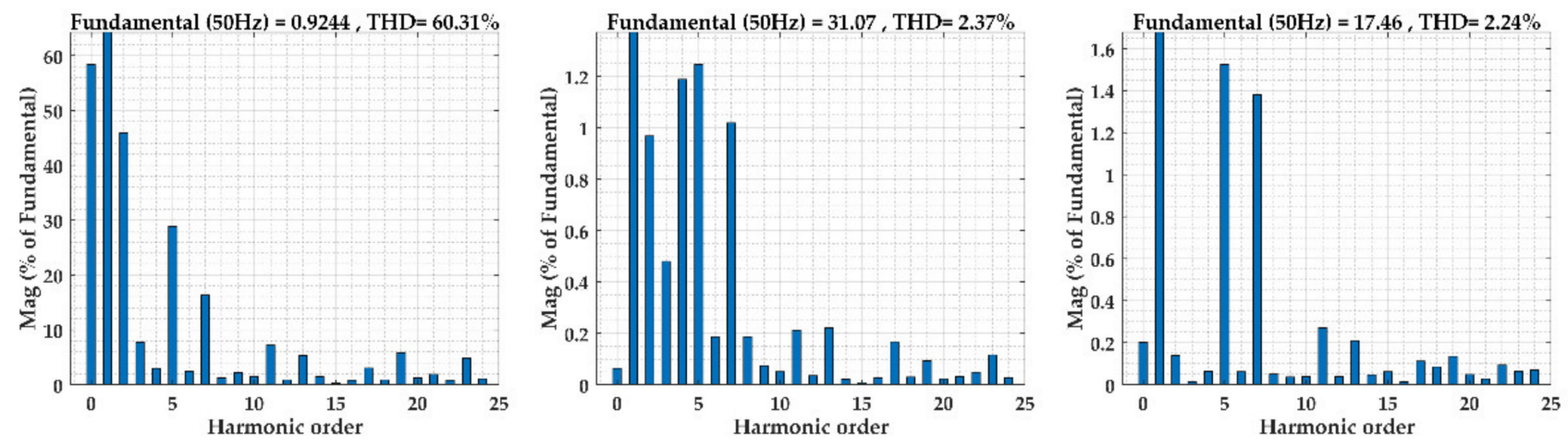

(b)

Figure 4. Simulation results: (a) Three phase voltages and currents depending on the irradiance level; (b) harmonic spectra and $\mathrm{THD}_{\mathrm{I}}$ for each level of irradiance. 
It should be noted that waveforms in Figure $4 \mathrm{a}$ are not obtained continuously by changing the irradiance level. They are managed so that they can respond to different irradiance levels in a stationary mode. In this research, the emphasis has not been on the dynamic response of the inverter and its impact on harmonic behavior, but on the level of the THD factor, which implies a significant content of electric power quantities, especially the non-active parts.

Observing the harmonic spectra in Figure $4 \mathrm{~b}$, the low irradiance $(<10 \%)$ cause has a significant share of high-order harmonics in the output current. However, the THD I factor is calculated in relation to the fundamental harmonic, so that the value of fundamental harmonic will be lower within the lower irradiance, which may implicate the main reason for a drastic increase in the $\mathrm{THD}_{\mathrm{I}}$. In addition, the $\mathrm{THD}_{\mathrm{U}}$ value is important at the point of common coupling; therefore, this value will be low in the case of small or medium PV systems connected to the strong grid, besides the current harmonic injection.

By analyzing the PV power profiles (in Figure 2) in different weather conditions, it can be concluded that this significant share of high-order harmonics may take a certain period, which justifies the task of evaluation and analysis of electric power quantities.

\section{System Description and Experimental Setup}

\subsection{System Configuration}

The observed PV system is located on the rooftop of the building of the Faculty of Electrical Engineering in East Sarajevo $\left(43.8237^{\circ} \mathrm{N}, 18.3743^{\circ} \mathrm{S}\right)$. The installed $15.9 \mathrm{kWp}$ gridconnected system consists of 60 polycrystal modules with $265 \mathrm{Wp}$ each. These modules are connected in strings of 20 modules each, with two of these three strings in parallel. The Fronius SYMO 15.0-3-M inverter is used as a link between the PV array and grid, with a rated output power of $15 \mathrm{kVA}$. The input voltage range is 200-1000 VDC with a maximum efficiency occurrence at $\approx 600 \mathrm{VDC}$ of input voltage. This system is connected to the local facility distribution transformer, and it is used for local load supply, handing over the rest of the produced energy into the grid (Figure 5).

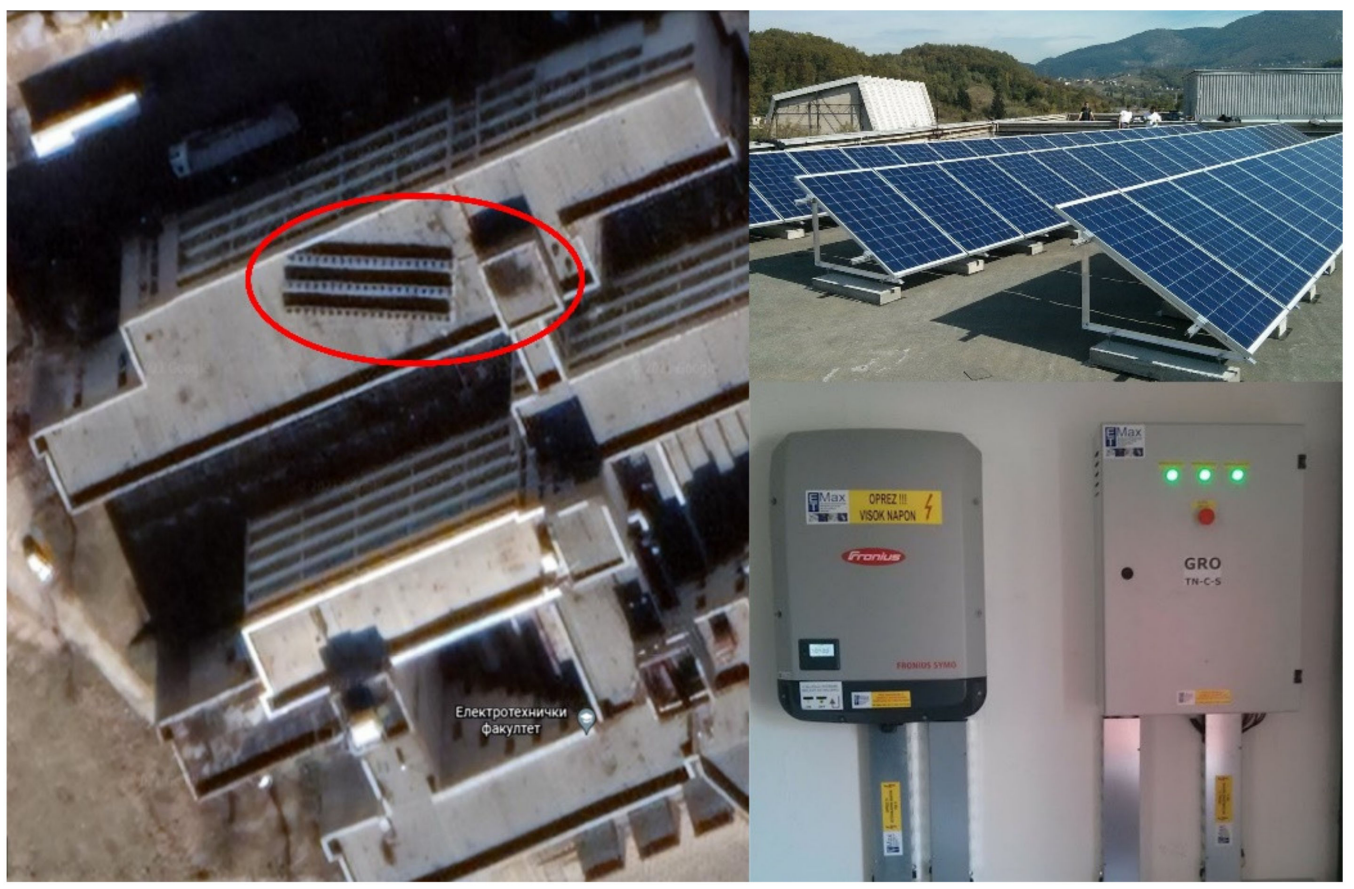

Figure 5. Location and disposition of the grid-connected PV system. 


\subsection{Measurement and Acquisition System}

The setup for the experimental part of this contribution is implemented as a measurement and parameter acquisition system consisting of fully isolated and multichannel voltage and current sensing modules [23], as well as a multifunctional input/output card (Humusoft MF 624 [24]). The measurement modules are designed to be used in a wide range of applications, such as for three-phase systems monitoring, power converters, motor drives, and PV monitoring applications. The voltage sensor ranges from $10 \mathrm{x}$ up to $100 \mathrm{~V}$, and from $100 \mathrm{x}$ up to $1000 \mathrm{~V}$, while the current sensing goes up to $100 \mathrm{~A}$. The applied MF 624 multifunction I/O card is generally used in the process of control and measurement applications. The board offers A/D conversion, D/A conversion, digital input, digital output, quadrature encoder input, timers, counters, $\mathrm{PWM}$, pulse, and frequency measurements. The boards contain 8 14-bit analog input channels with simultaneous samples, hold circuits, very short conversion time, 8 14-bit analog output channels, 8 digital inputs, 8 digital outputs, 4 encoder inputs with differential line receivers, and 4 counters or timers. The card is designed for standard data acquisition and control applications and optimized for use with Real Time Toolbox for Simulink ${ }^{\circledR}$ [25]. A block diagram of used components for measurement and acquisition setup is presented in Figure 6.

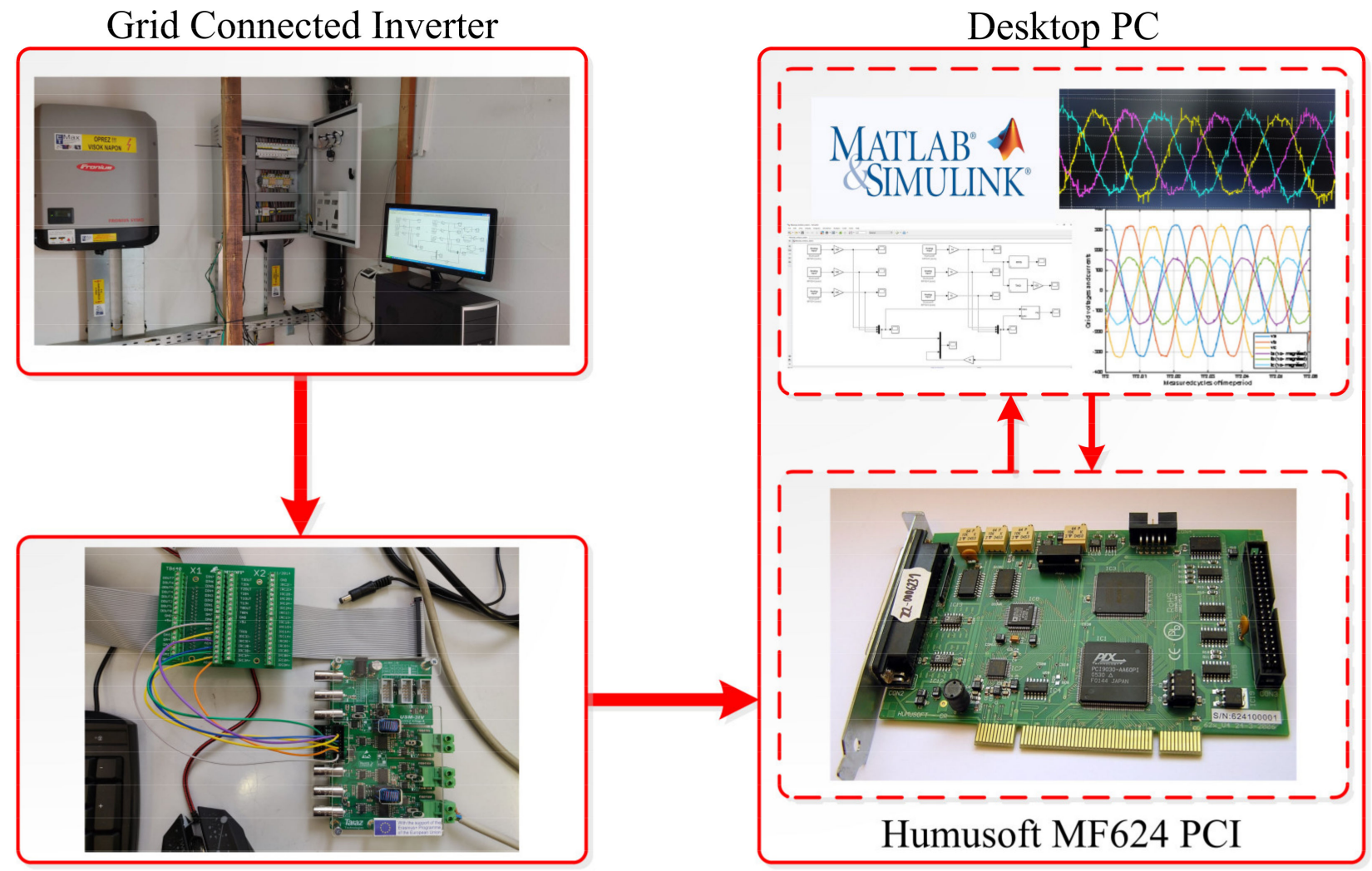

Measurement Unit

Figure 6. Block diagram of used components for measurement and acquisition setup.

\subsection{Experimental Results}

By analyzing the three cases defined in Table 1, the obtained results are shown in Figures 7-9. The evaluated power components, with the power factor, voltage and current waveforms, and harmonic spectra with $\mathrm{THD}_{\mathrm{I}}$ and $\mathrm{THD}_{\mathrm{U}}$ factors are presented. The evaluated values of the THD factors, electric power quantities, and the power factor are also given in Table 2. 


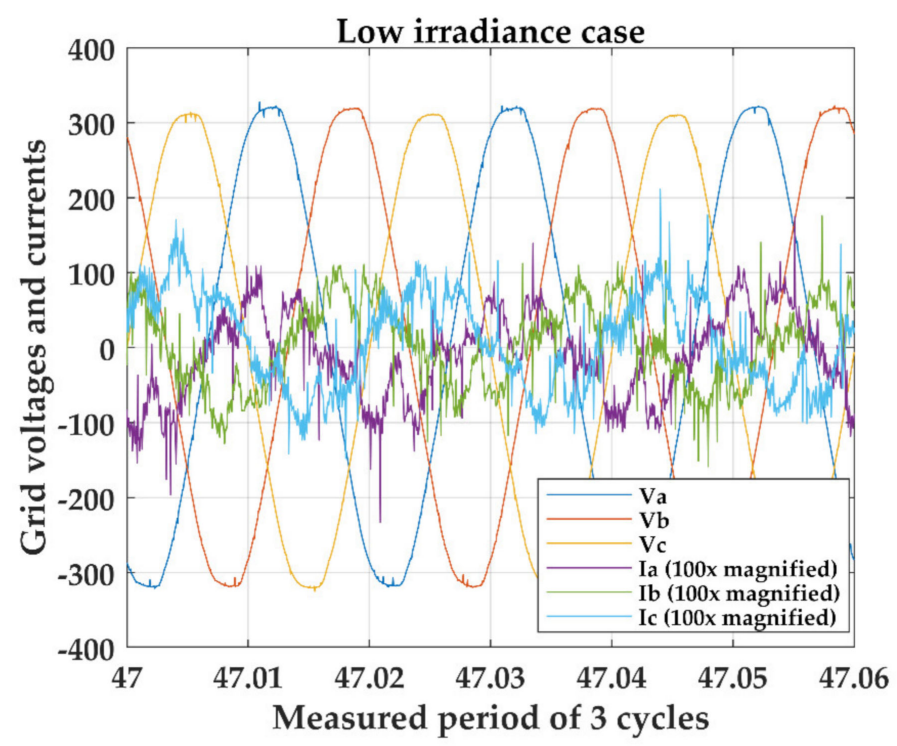

(a)

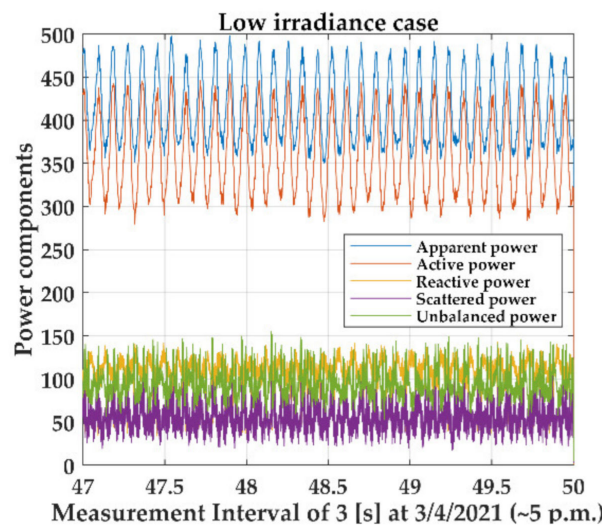

(b)

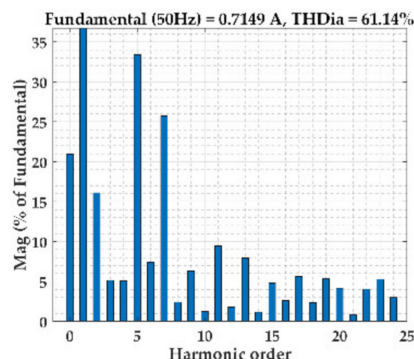

(d)

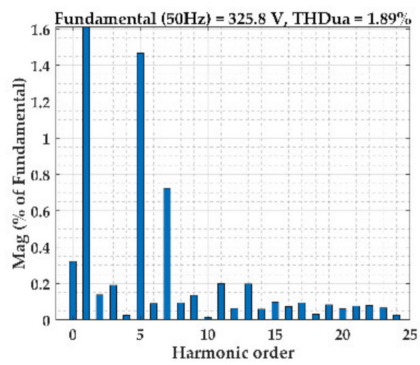

(g)

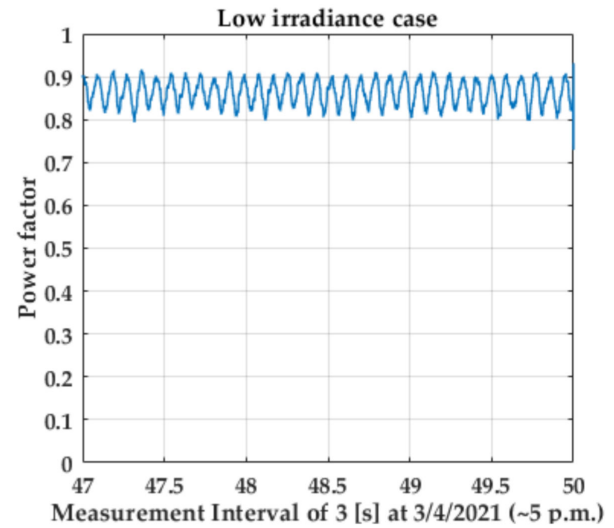

(c)

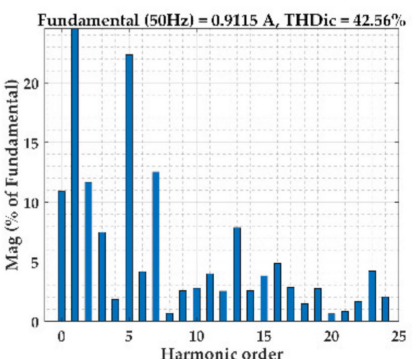

(f)

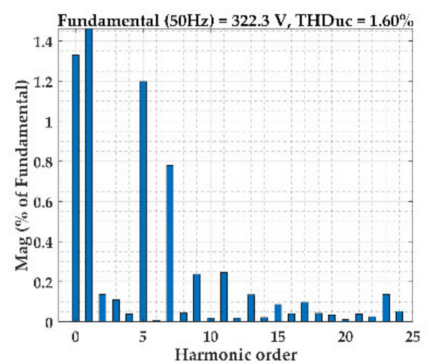

(i)

Figure 7. Experimental results for the low irradiance case: (a) Grid voltage and current waveforms; (b) power components according to CPC theory; (c) power factor; (d-f) harmonic spectra and THDI factors of inverter currents; (g-i) harmonic spectra and THD $\mathrm{U}$ factors of grid voltages. 


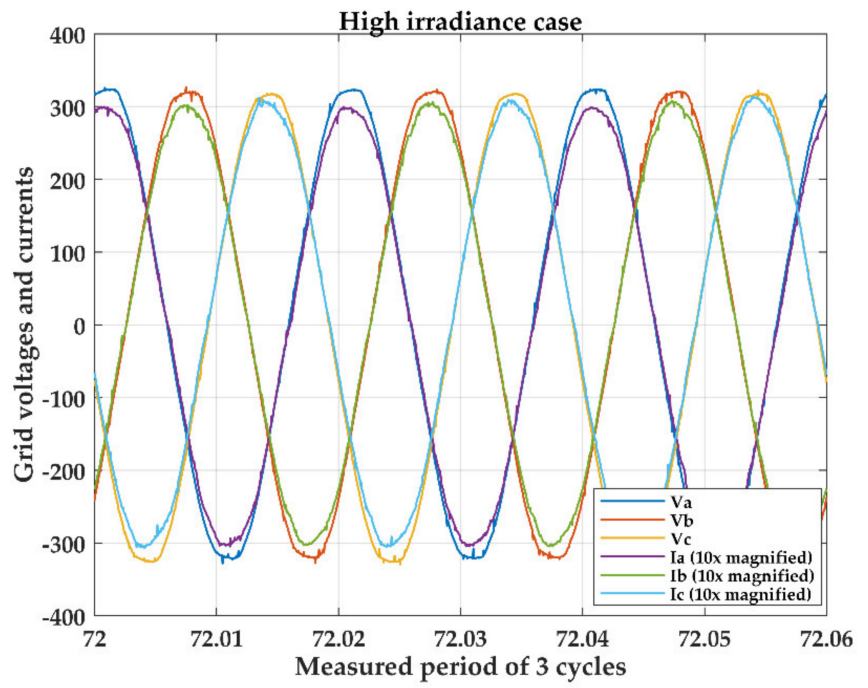

(a)

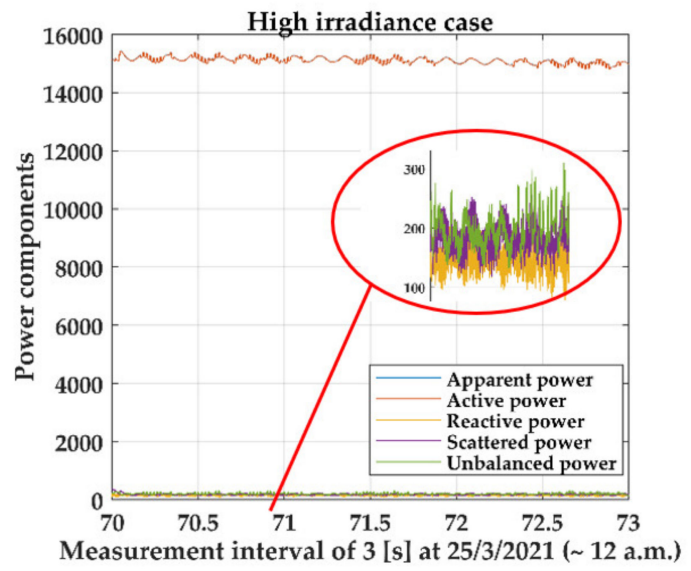

(b)

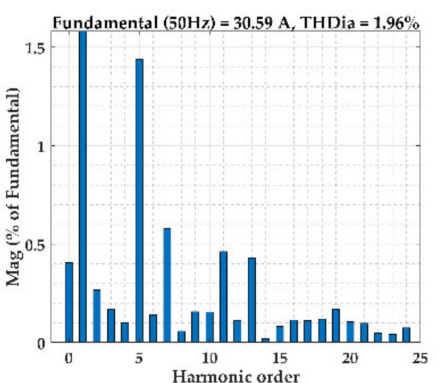

(d)

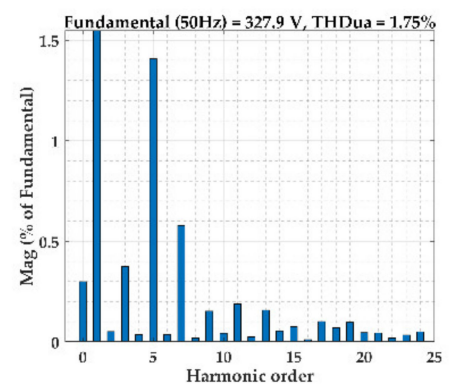

(g)

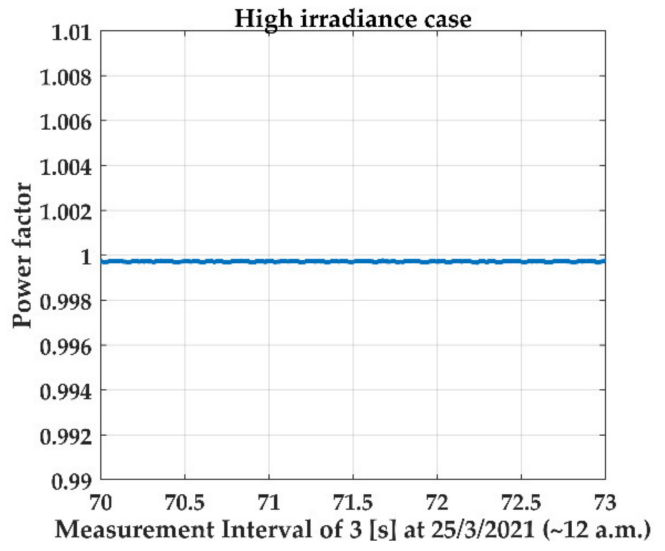

(c)

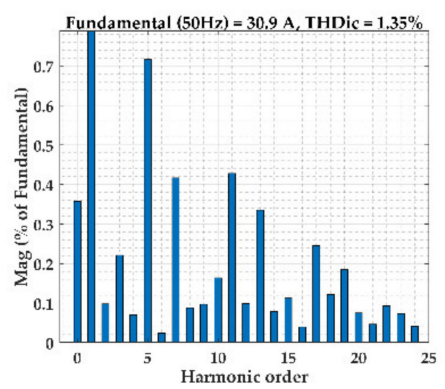

(f)

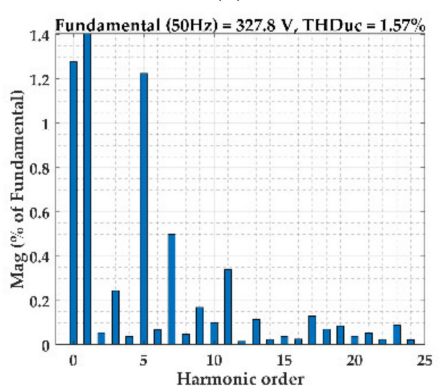

(i)

Figure 8. Experimental results for the high irradiance case: (a) Grid voltage and current waveforms; (b) power components according to CPC theory; (c) power factor; (d-f) harmonic spectra and THD factors of inverter currents; $(\mathrm{g}-\mathbf{i})$ harmonic spectra and $\mathrm{THD}_{\mathrm{U}}$ factors of grid voltages. 


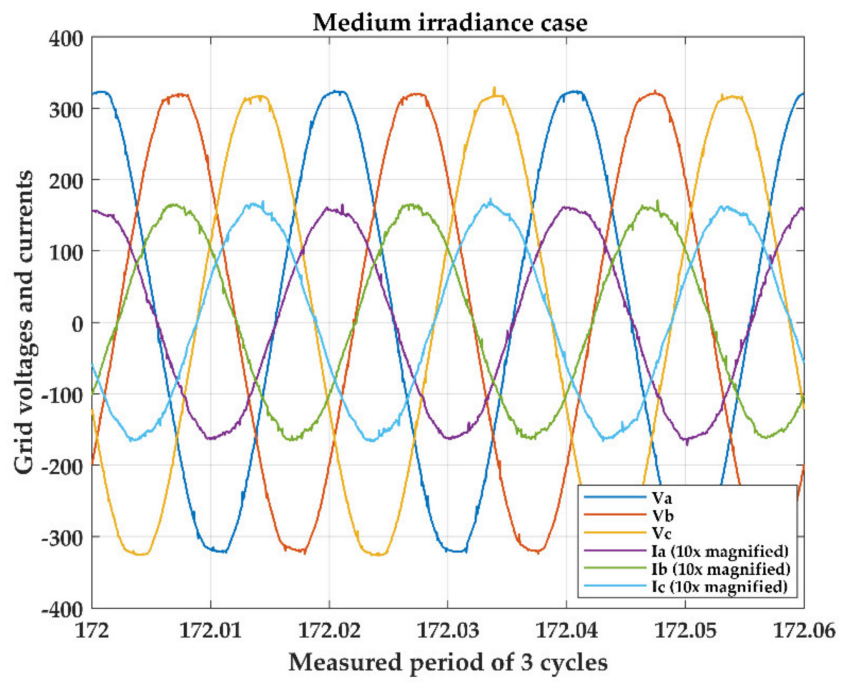

(a)

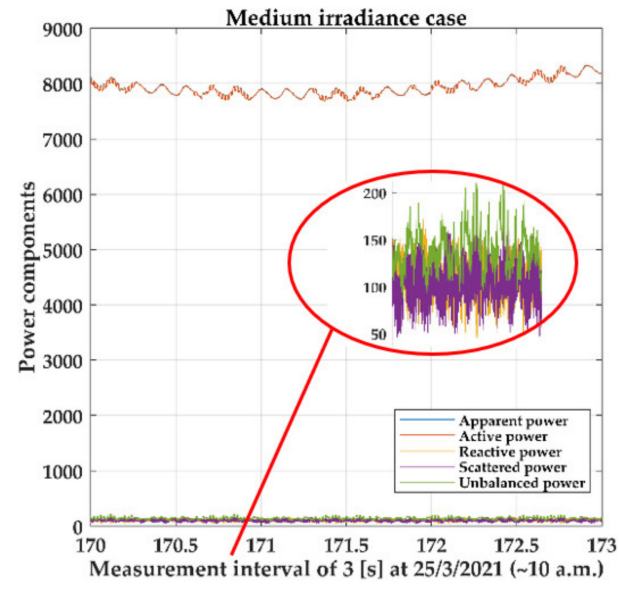

(b)

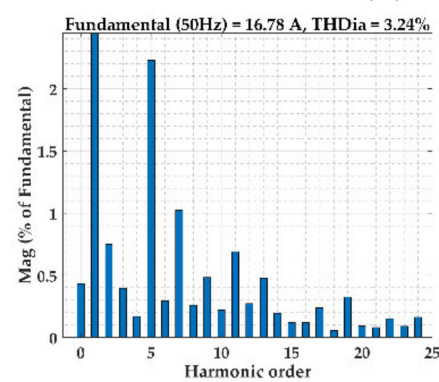

(d)

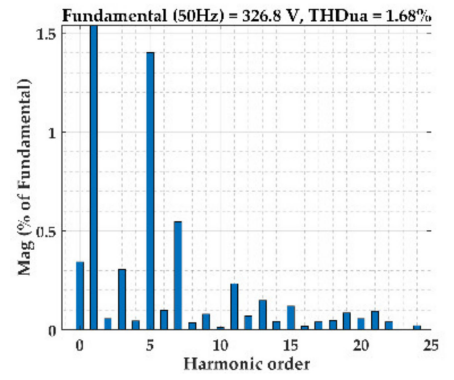

(g)

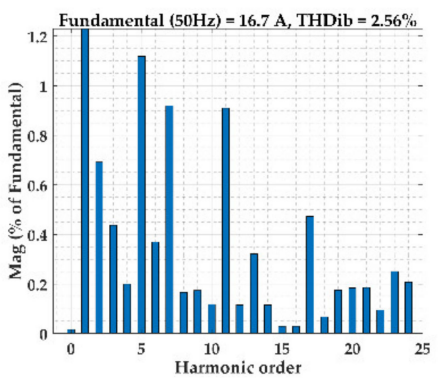

(e)

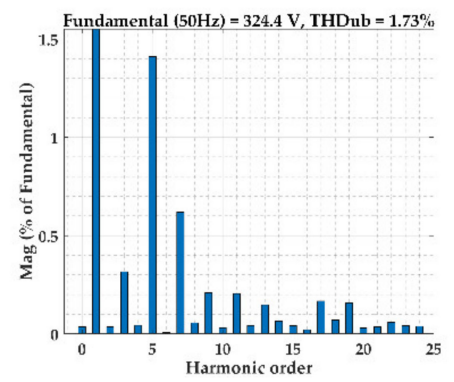

(h)

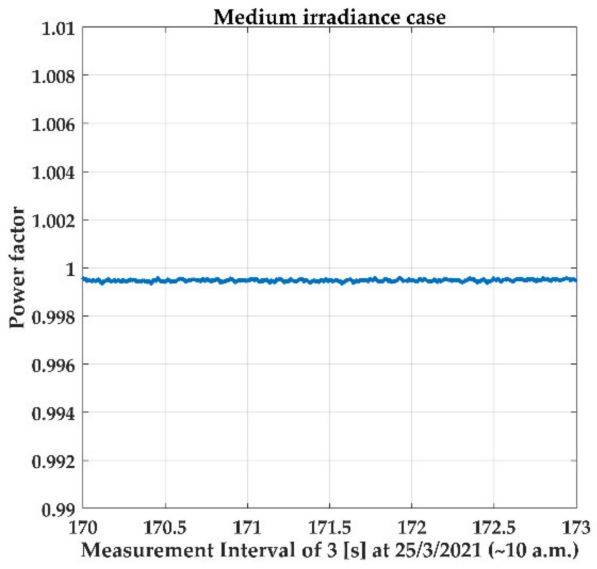

(c)

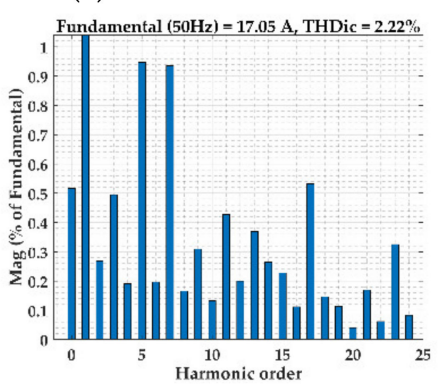

(f)

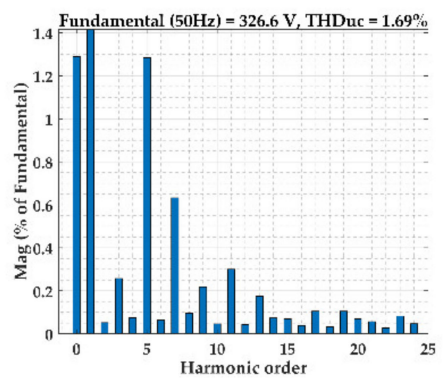

(i)

Figure 9. Experimental results for the medium irradiance case: (a) Grid voltage and current waveforms; (b) power components according to CPC theory; (c) power factor; (d-f) harmonic spectra and $\mathrm{THD}_{\mathrm{I}}$ factors of inverter currents; $(\mathrm{g}-\mathbf{i})$ harmonic spectra and $\mathrm{THD}_{\mathrm{U}}$ factors of grid voltages. 
Table 2. The values of the parameters in an experimental approach for three different cases.

\begin{tabular}{|c|c|c|c|}
\hline & \multicolumn{3}{|c|}{ Irradiance Level } \\
\hline & $\begin{array}{c}\text { Low } \\
(<10 \% \text { of Nominal) }\end{array}$ & $\begin{array}{c}\text { Medium } \\
(\approx 50 \% \text { of Nominal })\end{array}$ & $\begin{array}{c}\text { High } \\
(100 \% \text { of Nominal) }\end{array}$ \\
\hline $\mathrm{THD}_{\mathrm{Ua}}(\%)$ & 1.89 & 1.68 & 1.75 \\
\hline $\mathrm{THD}_{\mathrm{Ub}}(\%)$ & 1.80 & 1.73 & 1.79 \\
\hline $\mathrm{THD}_{\mathrm{Uc}}(\%)$ & 1.60 & 1.69 & 1.57 \\
\hline $\mathrm{THD}_{\text {Ia }}(\%)$ & 61.14 & 3.24 & 1.96 \\
\hline $\mathrm{THD}_{\mathrm{Ib}}(\%)$ & 41.47 & 2.56 & 1.62 \\
\hline $\mathrm{THD}_{\text {Ic }}(\%)$ & 42.56 & 2.22 & 1.35 \\
\hline$S$ (VA) & 416.1 & 8073.5 & 15,035 \\
\hline$P(\mathrm{~W})$ & 379.8 & 8069.4 & 15,031 \\
\hline$Q$ (Var) & 119.1 & 110.1 & 147.5 \\
\hline$D_{s}(\mathrm{VA})$ & 61.4 & 115.7 & 208.1 \\
\hline$D_{u}(\mathrm{VA})$ & 105.3 & 140.7 & 197.7 \\
\hline $\mathrm{PF}$ & 0.8691 & 0.9995 & 0.9997 \\
\hline
\end{tabular}

For the low irradiance case, when the power production is lower than $10 \%$, the power factor is significantly lower than 1 (primarily as a consequence of current distortion), whereby the non-active power components are comparable to the value of active power. The impact of these components is also visible in the current waveforms, resulting in a high $\mathrm{THD}_{\text {Ia }}$ factor of $61.14 \%\left(\mathrm{THD}_{\mathrm{Ib}}=41.47 \%\right.$ and $\mathrm{THD}_{\mathrm{Ic}}=42.56 \%$ are lower than $\mathrm{THD}_{\mathrm{Ia}}$, but still relatively high, which is expected when looking at the waveform). According to the results in Figure 2, with a longer low irradiance period during the day, the distortion effect can be a significant issue.

Unlike the low irradiance case, the cases with high and medium solar irradiance do not have a significant impact concerning the distortion effect. The voltage and current waveforms are practically in an ideal sinusoidal shape; therefore, the $\mathrm{THD}_{\mathrm{I}}$ factors are in the low range (for example, $\mathrm{THD}_{\mathrm{Ia}}$ is $2.14 \%$ in the high irradiance case, and $2.61 \%$ in the medium irradiance case). In addition, in these cases, all power components or electric power quantities can be evaluated, but their impact on total power is almost negligible and therefore the power factor almost reaches the value 1.

Observing the results from Table 2, it is found that the share of the non-active power components in the apparent power depends on the irradiance level. The distortion power $D_{s}$ and the unbalanced power $D_{u}$ are lower in the case with lower irradiance, but their share in the apparent power is significantly higher than the share of the same components in the other two cases.

On the other hand, the impact of harmonic injection to the grid voltage did not come into question because the short circuit power, at the point of common coupling, is much higher than the installed power of the connected PV system. In all three cases, the $\mathrm{THD}_{\mathrm{U}}$ factor remained less than $2 \%$.

In addition, from Figures 7-9, it is observed that a certain share of fifth and seventh harmonics from the grid voltage are driven to the current's spectra. This phenomenon is justified by the existence of a Phase-Locked Loop (PLL) structure in the control structure of a grid-connected inverter. Therefore, it can be concluded that this share of fifth and seventh harmonics in the current spectra is most likely a consequence of their existence in the grid voltage. 


\section{Comparison of the Simulation and Experiment Results}

As mentioned previously, the emphasis in this research is on the level of the THD factors, which imply significant content of the non-active power. By analyzing the $\mathrm{THD}_{\mathrm{I}}$ factor in different weather conditions, it can be concluded that this significant share of high-order harmonics may cause different levels of electric power quantities. Different mitigation techniques and the optimal design of a grid-side filter, with improved control algorithms, could suspense and reduce the share of harmonic injection. The developed simulation model of a real PV system (although with a lack of manufacturer information for the grid-connected inverter) provides a better understanding of the whole process and a comparison of results. Figure 10 shows a bar graph comparison of the $\mathrm{THD}_{\mathrm{Ia}}$ factor obtained for the simulation and experimental results for three different cases. From graphs, slightly different harmonics shares for each case are observed. Differences between simulation and experimental results, in terms of harmonic-order share, can be justified with a lack of manufacturer information for the used grid inverter. Namely, the same inverter was not used in the simulation such as the one implemented in the used inverter, nor was the same control algorithm used.

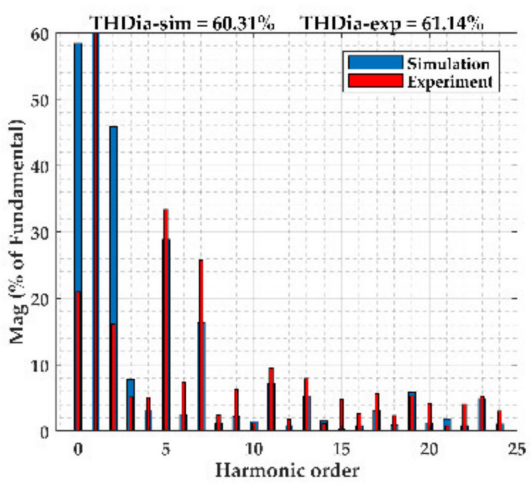

(a)

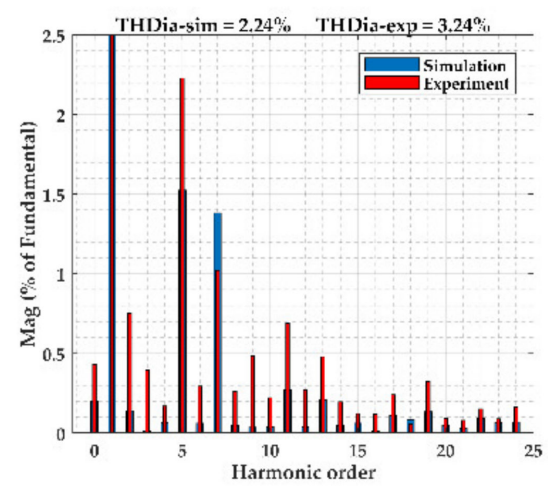

(b)

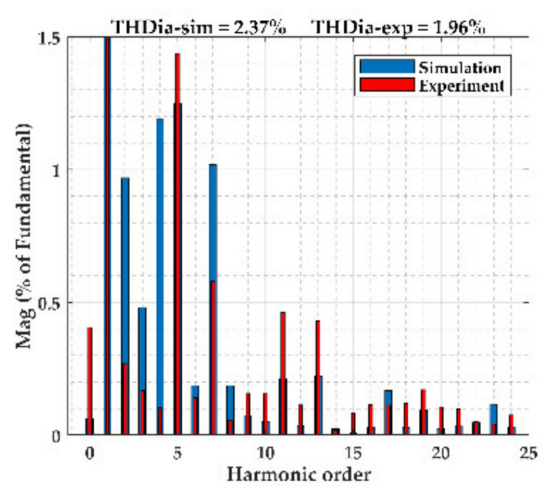

(c)

Figure 10. Comparison of simulation and experimental results using $\mathrm{THD}_{\mathrm{Ia}}$ factor for three different cases: (a) Low irradiance case; (b) medium irradiance case; (c) high irradiance case.

\section{Conclusions}

Followed by the announcements of future investments in renewable energy sources, especially with an emphasis on grid-connected PV systems, the energy growth trend is certain, as well as its consequent impact on the power system. Power quality issues and the hosting capacity issue will be the major tasks of future research. Corresponding to that, this article points out the electric power quantities evaluation and followed distortion effects, as the factors that should be considered very important in planning and installing a new PV capacity.

Distortion effects concerning the power quality issues and the impact of the power components were presented for three different cases, depending on different solar irradiances, and based on the implemented simulation model and experimental measurement in real time. By analyzing the results of the simulation model, as well as the experimental setup, it can be concluded that a major issue comes from a low PV power production because of the low irradiation level. The PV inverters appear as generators of the significant share of high-order current harmonics, which result in the existence of a valuable amount of electric power quantities. The low-power factor becomes predominantly dependent on the distortion effect and its value strongly depends on the non-active scattered power component.

It is noted that this impact is not significant from the point of view of the amount of power injected into the grid in bad weather conditions, but it can be assumed that there 
will be a significant number of installed grid-connected PV systems in some micro-location in the future; therefore, this impact will gradually gain importance.

Author Contributions: Formal analysis, M.I.; Investigation, M.I. and J.M.; Methodology, M.I. and J.M.; Supervision, J.M.; Writing—original draft, M.I.; Writing—review \& editing, M.I. and J.M. All authors have read and agreed to the published version of the manuscript.

Funding: This research received no external funding.

Acknowledgments: The authors would like to express their gratitude to the staff of the ELEMEND Laboratory from University of East Sarajevo, which provided equipment for experimental purposes (equipment is supported by the Erasmus+ project ELEMEND 585681-EEP-1-2017-1-EL-EPPKA2CBHE-JP). The authors are also grateful to the Ministry of Science and Technological Development of Serbia for helping this research through the technological projects III42009 and TR-33037.

Conflicts of Interest: The authors declare no conflict of interest.

\section{References}

1. Our World in Data. Available online: www.ourworldindata.org (accessed on 25 August 2021).

2. Demirok, E.; González, P.C.; Frederiksen, K.H.B.; Sera, D.; Rodriguez, P.; Teodorescu, R. Local Reactive Power Control Methods for Overvoltage Prevention of Distributed Solar Inverters in Low-Voltage Grids. IEEE J. Photovolt. 2011, 1, 174-182. [CrossRef]

3. Patsalides, M.; Evagorou, D.; Makrides, G.; Achilides, Z.; Georghiou, G.; Stavrou, A.; Efthimiou, V.; Zinsser, B.; Schmitt, W.; Werner, J. The Effect of Solar Irradiance on the Power Quality Behaviour of Grid Connected Photovoltaic Systems. Renew. Energy Power Qual. J. 2007, 1, 323-330. [CrossRef]

4. Zainuddin, M.; Surusa, F.; Syafaruddin; Manjang, S. The Effect of Irradiance on Distribution Power System Stability in LargeScale Grid-Connected Photovoltaic. In Proceedings of the 2019 International Conference on Information and Communications Technology (ICOIACT), Yogyakarta, Indonesia, 24-25 July 2019; pp. 805-810.

5. De Silva, H.H.H.; Jayamaha, D.K.J.S.; Lidula, N.W.A. Power Quality Issues Due to High Penetration of Rooftop Solar PV in Low Voltage Distribution Networks: A Case Study. In Proceedings of the IEEE 14th International Conference on Industrial and Information Systems (ICIIS), Kandy, Sri Lanka, 18-20 December 2019; pp. 395-400.

6. Elkholy, A. Harmonics assessment and mathematical modeling of power quality parameters for low voltage grid connected photovoltaic systems. Sol. Energy 2019, 183, 315-326. [CrossRef]

7. Al-Shetwi, A.Q.; Hannan, M.A.; Jern, K.P.; Alkahatani, A.A.; PG Abas, A.E. Power Quality Assessment of Grid-Connected PV System in Compliance with the Recent Integration Requirements. Electronics 2020, 9, 366. [CrossRef]

8. Smith, J.; Rönnberg, S.; Bollen, M.; Meyer, J.; Blanco, A.; Koo, K.L.; Mushamalirwa, D. Power Quality Aspects for Solar Power. CIGRE Working Group JWG C4/C6.29. CIRED-Open Access Proc. J. 2017, 2017, 809-813. [CrossRef]

9. Ouai, A.; Mokrani, L.; Machmoum, M.; Houari, A. Control and energy management of a large scale grid-connected PV system for power quality improvement. Sol. Energy 2018, 171, 893-906. [CrossRef]

10. Khomsi, C.; Bouzid, M.; Jelassi, K. Power Quality Improvement in a Three-Phase Grid Tied Photovoltaic System Supplying Unbalanced and Nonlinear Loads. Int. J. Renew. Energy Res. 2018, 8, 1165-1177.

11. Reddy, C.; Goud, B.; Aymen, F.; Rao, G.S.; Bortoni, E. Power Quality Improvement in HRES Grid Connected System with FOPID Based Atom Search Optimization Technique. Energies 2021, 14, 5812. [CrossRef]

12. IEEE Standard 1459; IEEE Standard Definitions for the Measurement of Electric Power Quantities under Sinusoidal, NonSinusoidal, Balanced or Unbalanced Conditions. IEEE Power \& Energy Society: New York, NY, USA, 2010.

13. Mikulović, J. Power Definitions for Electrical Circuits with Harmonic Distortions of Voltages and Currents. In Proceedings of the 18th International Symposium INFOTEH-JAHORINA, Jahorina, Bosnia and Herzegovina, 20-22 March 2019; pp. 34-42.

14. Czarnecki, L.S. Currents' Physical Components (CPC) Concept: A Fundamental of Power Theory. In Proceedings of the International School on Nonsinusoidal Currents and Compensation (ISNCC), Lagow, Poland, 10-13 June 2008.

15. Czarnecki, L.S. Orthogonal decomposition of the currents in a 3-phase nonlinear asymmetrical circuit with a nonsinusoidal voltage source. IEEE Trans. Instrum. Meas. 1988, 37, 30-34. [CrossRef]

16. Czarnecki, L.S. Physical Interpretation of the Reactive Power in Terms of CPC Power Theory. Electr. Power Qual. Util. 2007, 13, 89-95.

17. Ahsan, S.M.; Khan, H.A.; Hussain, A.; Tariq, S.; Zaffar, N.A. Harmonic Analysis of Grid-Connected Solar PV Systems with Nonlinear Household Loads in Low-Voltage Distribution Networks. Sustainability 2021, 13, 3709. [CrossRef]

18. Liang, X.; Andalib-Bin-Karim, C. Harmonics and Mitigation Techniques Through Advanced Control in Grid-Connected Renewable Energy Sources: A Review. IEEE Trans. Ind. Appl. 2018, 54, 3100-3111. [CrossRef]

19. Michalec, Ł.; Jasiński, M.; Sikorski, T.; Leonowicz, Z.; Jasiński, Ł.; Suresh, V. Impact of Harmonic Currents of Nonlinear Loads on Power Quality of a Low Voltage Network-Review and Case Study. Energies 2021, 14, 3665. [CrossRef] 
20. Arzani, A.; Arunagirinathan, P.; Venayagamoorthy, G.K. Development of Optimal PI Controllers for a Grid-Tied Photovoltaic Inverter. In Proceedings of the IEEE Symposium Series on Computational Intelligence (SSCI), Cape Town, South Africa, 7-10 December 2015; pp. 1272-1279.

21. Chen, M.-R.; Wang, H.; Zeng, G.-Q.; Dai, Y.-X.; Bi, D.-Q. Optimal P-Q Control of Grid-Connected Inverters in a Microgrid Based on Adaptive Population Extremal Optimization. Energies 2018, 11, 2107. [CrossRef]

22. Deželak, K.; Bracinik, P.; Sredenšek, K.; Seme, S. Proportional-Integral Controllers Performance of a Grid-Connected Solar PV System with Particle Swarm Optimization and Ziegler-Nichols Tuning Method. Energies 2021, 14, 2516. [CrossRef]

23. Taraz Technologies. Available online: www.taraztechnologies.com (accessed on 31 August 2021).

24. Humusoft. Available online: www.humusoft.cz (accessed on 31 August 2021).

25. MathWorks. Available online: www.mathworks.com (accessed on 31 August 2021). 